\title{
The origin of clamped and clampless basidia in Armillariella ostoyae
}

\author{
KARI KORHONEN
}

\begin{abstract}
KORHONEN, K. 1980: The origin of clamped and clampless basidia in Armillariella ostoyae. - Karstenia 20: $23-27$.

In the laboratory diploid pure cultures of $A$. ostoyae Romagn. produce fruit bodies with clampless basidia, whereas the natural fruit bodies of this species have basidia with a basal clamp. In nature the basidia develop from dikaryotic subhymenial cells with haploid nuclei and two nuclei fuse in the basidium. In pure culture the basidia develop from uninucleate diploid cells and no fusion of nuclei takes place in the basidium. Reduction of genetic material in fruit body primordia apparently precedes the development of subhymenial hyphae in nature. Such reduction does not take place in pure culture.
\end{abstract}

Kari Korhonen, The Finnish Forest Research Institute, Unioninkatu 40 A, SF 00170 Helsinki 17, Finland.

Recent investigations based on mating experiments have shown that the Armillariella (Armillaria) mellea complex consists of several intersterility groups or 'biological species' in North America and Europe (Ullrich \& Anderson 1978, Korhonen 1978, Anderson \& Ullrich 1979). Cytological and genetic studies have also revealed that the fungi belonging to this complex have an unusual nuclear cycle with a transient dikaryotic phase followed by somatic diploidization in mating (Hintikka 1973, Korhonen \& Hintikka 1974), a prolonged diploid vegetative stage (Ullrich \& Anderson 1978, Peabody et al. 1978), and a reduction of genetic material in the gill trama of fruit body primordia prior to the development of basidia (Tommerup \& Boradbent 1975).

In some fruit body collections of Armillariella, the basidia have a basal clamp, while in others the basidia are clampless (Singer 1956, Romagnesi 1970, 1973, Peabody \& Motta 1979). Among the five biological species of the $A$. mellea complex so far reported from Europe, four seem to have clamped basidia and one is clampless (Korhonen 1978).

The clamped basidia originate from dikaryotic subhymenial cells and two nuclei fuse in the basidium (Ruhland 1901, Tommerup \& Broadbent 1975, Peabody et al. 1978). The development of the clampless basidia was studied by Kniep (1911) in pure culture, the basidia being formed directly on the surface of the vegetative mycelium. These basidia originated from uninucleate cells and no fusion of nuclei took place in the basidium. Kniep $(1911,1928)$ supposed that the basidia and subhymenial cells were haploid. Both the clamped and clampless basidia of Armillariella produce four spores.

The great difficulty in producing fruit bodies of Armillariella in pure culture has formed an obstacle to life cycle studies. It has recently been shown, however, that one European species, A. ostoyae Romagn. (= 'species C' of Korhonen 1978), fruits guite readily in pure culture (Rykowski 1974, Jacques-Félix 1977, Lung-Escarmant 1978). The mechanism of somatic diploidization in this species and the existence of clamped basidia in the natural fruit bodies have been reported earlier (Korhonen 1978). The clamped basidia are presumably the result of prebasidial haploidization, which takes place in the fruit body primordia.

The primary aim of this study was to investigate prebasidial haploidization in the fruit bodies of $A$. ostoyae produced in pure culture. Surprisingly, however, no signs of this phenomenon were found and only fruit bodies with clampless basidia developed in our laboratory. The origin and development of the clamped and clampless basidia of A. ostoyae are compared in this report. 


\section{Material and methods}

The identification of the Finnish Armillariella material used in this study was checked in haploid-haploid or diploidhaploid pairings (Korhonen 1978) against three collections of $A$. ostoyae identified on the basis of fruit bodies and kindly delivered by Dr. Henri Romagnesi, Paris, Dr. Roy Watling, Edinburgh, and Dr. Brigitte Lung-Escarmant, Bordeaux.

Two diploid pure cultures of $A$. ostoyae were used for producing fruit bodies in the laboratory. Culture I was isolated in 1976 from the wood of a dead Pinus sylvestris L. sapling in Luumäki, South-East Finland. Culture II is the product of a compatible mating between two monosporous strains, one of them originating from a fruit body on a $P$. sylvestris sapling in Tenala, South-West Finland, 1974, and the other from a fruit body on living Alnus incana (L.) Moench in Helsinki, 1974.

A single hyphal tip cell containing one nucleus (checked by phase contrast microscopy) was isolated from culture I and culture II. The mycelia originating from these cells were used in the experiments.

The methods for producing fruit bodies of Armillariella were suggested by C.G. Shaw, III, R. Watling, and G. Kile (personal communication). The usual culture medium contained $30 \mathrm{~g}$ malt extract (Bacto), $20 \mathrm{~g}$ glucose, $5 \mathrm{~g}$ peptone (Bacto), $19 \mathrm{~g}$ agar (Bacto) and $1000 \mathrm{ml}$ distilled water. Corn and barley grains moistened with $2 \%$ malt extract solution were also used. Some of the culture media were supplemented with 0.1 ppm sodium pentachlorophenol (Rykowski 1974). One hundred or two hundred milliliters of the medium was poured into 250 or $500 \mathrm{ml}$ conical flasks and autoclaved. The cultures were first incubated in the dark at $20-22^{\circ} \mathrm{C}$ for 3 weeks and then in continuous light at $18^{\circ} \mathrm{C}$ (light source: $15 \mathrm{~W}$ fluorescent tube at a distance of $30-40 \mathrm{~cm}$ from the cultures). The effect of cold shock at $4^{\circ} \mathrm{C}$ for 3 days following the dark incubation period was tested with some cultures.

The gills of the natural fruit bodies of $A$. ostoyae (collected in October and November 1979 in Luumäki, Helsinki, and Nurmijärvi) and of the fruit bodies produced in pure culture were fixed in a mixture of ethanol and acetic acid $(3: 1)$. The nuclei were stained by the HC1-Giemsa method (Korhonen \& Hintikka 1974).

The four spores formed on a single basidium were isolated for spore tetrad analysis (Esser \& Kuenen 1967) by the method of Epp (1977).

\section{Results}

Both isolates produced fruit bodies in 2-5 months on all the nutrient media, with or without added sodium pentachlorophenol. Cold shock treatment at $4^{\circ} \mathrm{C}$ was not necessary but appeared to shorten the time needed for fruit body initiation.

The fruit bodies grown in the laboratory usually had a more or less deformed external appearance, but a few quite natural-looking fruit bodies developed, too (Fig. 3). All the fruit bodies produced viable spores but the sporulation was never as abundant as in natural fruit bodies. The germination percentage of the spores on malt extract agar was usually high.
No dikaryotic cells with clamp connections were found in these fruit bodies. The basidia originated from uninucleate subhymenial cells and only one nucleus moved into the young basidium (Fig. 4). There was often a hook without any septum at the base of the basidium. Four uninucleate spores formed on each basidium.

The diploidy of the basidial nucleus was proved by spore tetrad isolation and by identifying the incompatibility factors in the members of the tetrads. Altogether 17 tetrads with three our four viable (germinating) spores were analyzed from one fruit body of culture II. Two different A and B incompatibility factors were found among the members of each tetrad, indicating that the tetrads originated from a diploid nucleus. The ratio between ditype and tetratype tetrads was 15:2. Eight of the ditype tetrads were parental and seven nonparental. The frequencies of different mating types among monosporous isolates were AxBx 16, AyBy 16, AxBy 18, AyBx 18.

The clamped basidia in the natural fruit bodies of A. ostoyae (Fig. 1) developed from dikaryotic subhymenial cells with clamp connections (Fig. 2). Two nuclei moved into the young basidium, where they fused. Four uninucleate spores were produced in a basidium. Altogether 27 spore tetrads were isolated from two natural fruit bodies collected from different sites. The germination percentage, however, was very low and only from one fruit body could eight tetrads be obtained with three or four viable spores. Among them, six were ditype and two tetratype tetrads. The frequencies of different mating types were $\mathrm{AxBx} 6$, AyBy 6, AxBy 10, and AyBx 10.

\section{Discussion}

The fruiting cultures of $A$. ostoyae originated from a single uninucleate hyphal tip cell of a vegetative mycelium. Two A and two B incompatibility factors were recovered from the basidiospore offspring, showing that the original uninucleate cell must have been diploid. This is further genetic proof of the diploidy of the vegetative mycelium of Armillariella (Ullrich \& Anderson 1978).

As the vegetative mycelium is diploid, the existence of haploid nuclei in dikaryotic subhymenial cells of many Armillariella collections is a peculiar phenomenon. The study of nuclear size by Tommerup and Broadbent (1975) indicates that the dikaryotic cells with haploid nuclei originate from diploid cells in fruit body primordia. The DNA measurements made by Peabody et al. (1978) seem to 

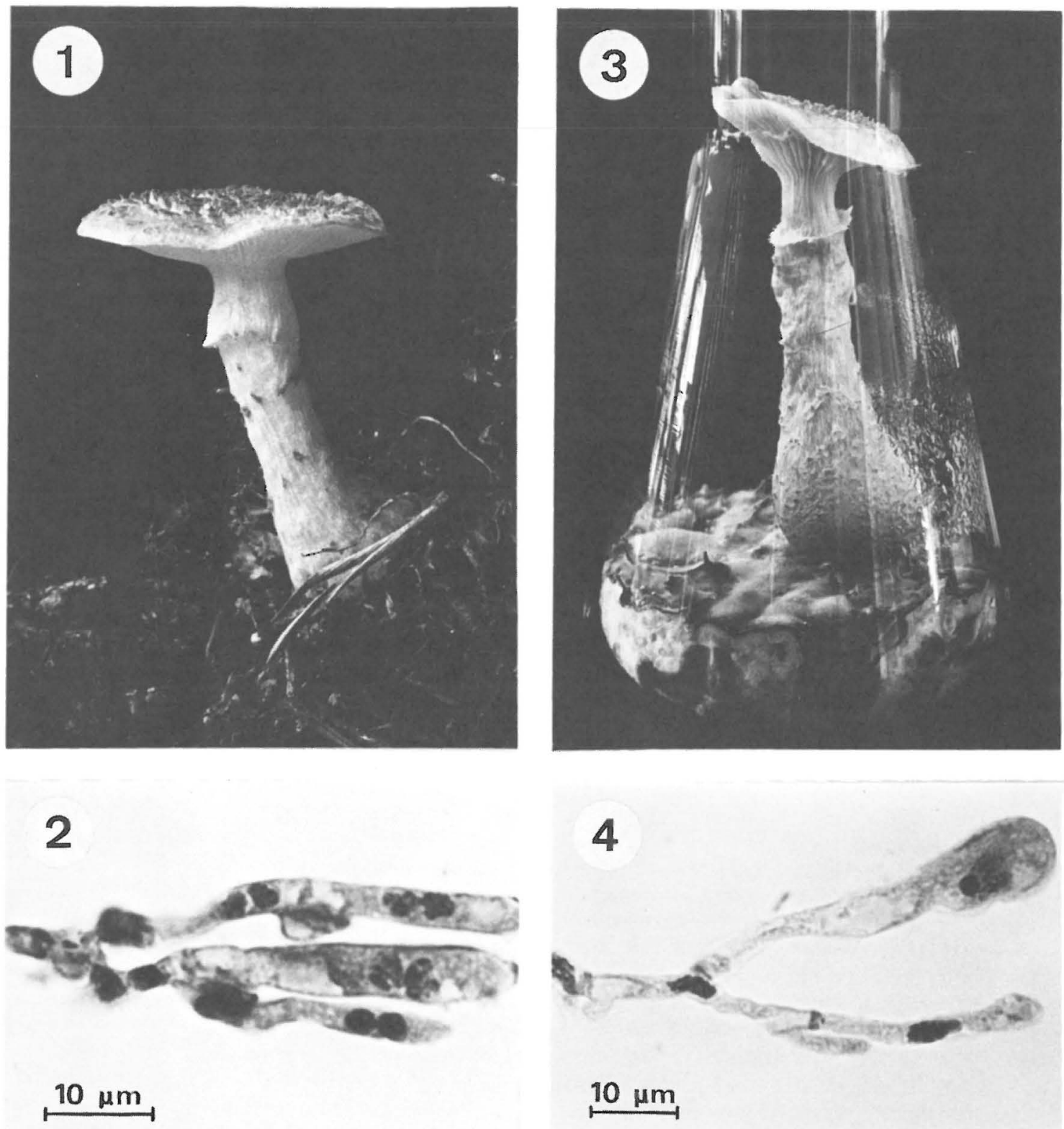

$10 \mu \mathrm{m}$

Figs. 1-4. Armillariella ostoyae. - 1: A natural fruit body. - 2: Dikaryotic sybhymenial hyphae from a natural fruit body. -3 : Fruit body produced in pure culture. -4 : Monokaryotic subhymenial hyphae from a fruit body produced in pure culture.

support this conclusion. The life cycle of Armillariella collections with clamped basidia thus seems to comprise two diploidizations and two haploidizations (Fig. 5).

On the other hand, genetic proof of the prebasidial haploidization is still lacking and the possibility that the haploid subhymenial nuclei of the natural fruit bodies of $A$. ostoyae can be traced back to mating cannot at present be completely excluded, although this alternative seems unlikely.

The results obtained in this study show that the basidia in this species complex may also develop 


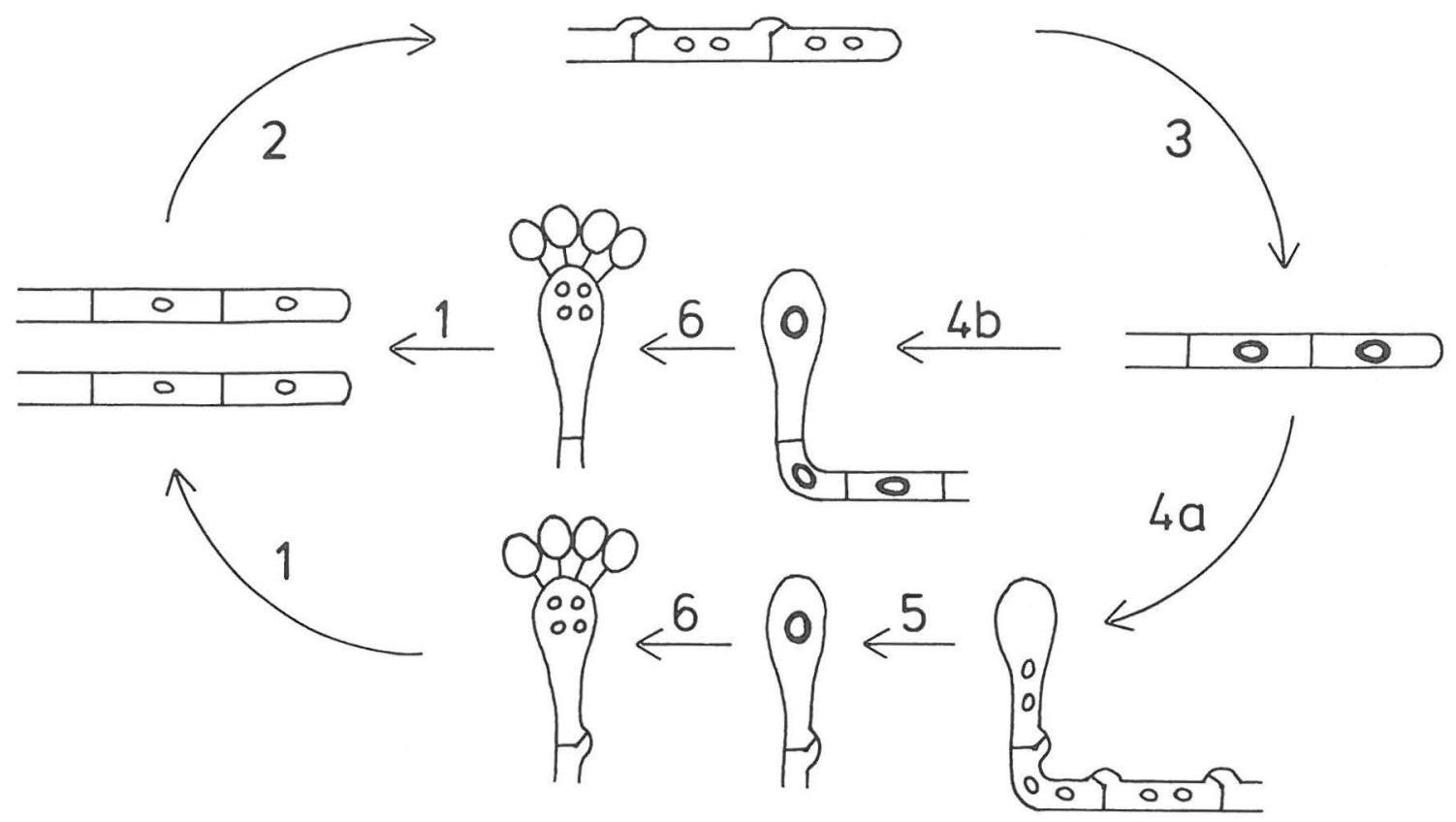

Fig. 5. The life cycle of $A$. ostoyae in pure culture and the probable life cycle in natural conditions. The haploid nuclei are drawn with a thin line and the diploid ones with a thick line. 1) Germination of basidiospores resulting in haploid monokaryotic mycelium. 2) Mating of compatible haploid mycelia, resulting in transient dikaryotic phase. 3) Somatic diploidization, resulting in diploid monokaryotic vegetative mycelium. 4a) Prebasidial reduction in fruit body primordia, resulting in dikaryotic subhymenial hyphae with haploid nuclei (in nature). 4b) Fruit body development without prebasidial reduction, resulting in diploid subhymenium (in pure culture). 5) Diploidization in the basidium (in nature). 6) Meiosis.

directly from diploid cells. As already suggested by Ullrich and Anderson (1978), this type of life cycle (Fig. 5) has no prebasidial reduction of genetic material and no diploidization in the basidium. It is probable that the clampless 'Mycelbasidien' studied by Kniep (1911) developed from diploid cells, too.

The results presented above suggest that the life cycle may proceed with or without prebasidial haploidization in the same biological species of Armillariella. So far, only evidence of the former pathway (basidia with a clamp) has been found in the natural fruit bodies of $A$. ostoyae in Finland (cf. Romagnesi 1970) and only the latter pathway has been found to occur in our laboratory. The reasons for the existence of different life cycles in nature and pure culture are unclear.

Some species or populations in the A. mellea complex have clampless basidia even in the natural fruit bodies (Singer 1956, Romagnesi 1973, Peabody \& Motta 1979). The ontogeny of the basidia in these groups has not yet been investigated. The life cycle of these clampless forms may be comparable with the simple diploid life cycle of $A$. ostoyae which takes place in laboratory conditions.

A possible explanation of the existence of prebasidial haploidization in the $A$. mellea complex could be that it may increase the frequency of genetic recombination. During the development of the natural fruit bodies of $A$. ostoyae crossing over may take place in both the prebasidial and basidial haploidization. In the laboratory fruit bodies it takes place only in the basidial reduction. Consequently, the frequency of tetratype tetrads, identifiable on the basis of incompatibility factors, should be higher in fruit bodies with prebasidial haploidization than in fruit bodies developing through a simple diploid life cycle. In order to prove this hypothesis, it would be necessary to produce clamped and clampless fruit bodies of the same isolate in approximately identical conditions, because the crossing over frequency may be closely dependent on the strain and the environmental factors (Esser \& Kuenen 1967). 


\section{References}

Anderson, J.B. \& Ullrich, R.C. 1979: Biological species of Armillaria mellea in North America. - Mycologia 71: 402-414

Epp, B.1). 1977: A rapid method for the isolation of tetrads in higher Basidiomycetes. - Mycologia 69: 210-211.

Esser, K. \& Kuenen, R. 1967: Genetics of fungi. - 500 pp. Berlin, Heidelberg, New York.

Hintikka, V. 1973: A note on the polarity of Armillariella mellea. - Karstenia 13: 32-39.

Jacques-Félix, M. 1977: Le complexe de l'Armillaire. Trav. déd. G. Viennot-Bourgin 1977: 143-157.

Kniep, H. 1911: Über das Auftreten von Basidien im einkerningen Mycel von Armillaria mellea Fl. Dan. Z. Bot. 3: $529-553$.

-"- 1928: Die Sexualität der niederen Pflanzen. - 544 pp. Jena.

Korhonen, K. 1978: Interfertility and clonal size in the Armillariella mellea complex. - Karstenia 18: 31-42.

Korhonen, K. \& Hintikka, V. 1974: Cytological evidence for somatic diploidization in dikaryotic cells of Armillariella mellea. - Arch. Microbiol. 95: 187-192.

I ung-Fscarmant, B. 1978: Contribution à l'étude de la biologie de l'Armillaire forme ostoyae et du probleme taxonomique d'Armillaria mellea (Vahl) Quél. - Thèse prèsentèe à l'Université de Bordeaux II. $135 \mathrm{pp}$.

Peabody, D.C. \& Motta, J.J. 1979: The ultrastructure of nuclear division in Armillaria mellea: meiosis I. Canad. J. Bot. 57: 1860-1872.

Peabody, D.C., Motta, J.J. \& Therrien 1978: Cytophotometric evidence for heteroploidy in the life cycle of Armillaria mellea. - Mycologia 70: 487-498.

Romagnesi, H. 1970: Observations sur les Armillariella (1). - Bull. Soc. Mycol. France 86: 257-268.

-"- 1973: Observations sur les Armillariella (2). - Bull. Soc. Mycol. France 89: 195-206.

Ruhland, W. 1901: Zur Kenntnis der intracellularen Karyogamie bei den Basidiomyceten. - Bot. Zeitung 59: $186-206$.

Rykowski, K. 1974: Observations on fructification of the honey fungus Armillariella mellea (Vahl) Karst. in pure cultures (in Polish, Engl. summary). - Prace Inst. Badawczego Leśnictwa 431: 1-21.

Singer, R. 1956: The Armillariella mellea group. - Lloydia 19: $176-187$

Tommerup, I.C. \& Broadbent, D. 1975: Nuclear fusion, meiosis and the origin of dikaryotic hyphae in Armillariella mellea. - Arch. Microbiol. 103: $279-282$.

Ullrich, R.C. \& Anderson, J.B. 1978: Sex and diploidy in Armillaria mellea. - Experimental Mycology 2: 119-129.

Accepted for publication

on July 14,1980 